\title{
ORIGINAL ARTICLE \\ Exploratory analysis of the visceral disease subgroup in a phase III study of abiraterone acetate in metastatic castration-resistant prostate cancer
}

\author{
OB Goodman Jr ${ }^{1,10}$, TW Flaig ${ }^{2,10}$, A Molina ${ }^{3}$, PFA Mulders ${ }^{4}, \mathrm{~K} \mathrm{Fizazi}^{5}, \mathrm{H}_{\text {Suttmann }}{ }^{6}, \mathrm{~J} \mathrm{Li}^{7}, \mathrm{~T} \mathrm{Kheoh}^{3}$, JS de Bono ${ }^{8}$ and HI Scher ${ }^{9}$
}

BACKGROUND: Visceral disease, non-nodal soft-tissue metastases predominantly involving the lung and liver, is a negative prognostic factor in patients with metastatic castration-resistant prostate cancer (mCRPC). An exploratory analysis of COU-AA-301 assessed whether abiraterone acetate (AA) improved overall survival (OS) in $\mathrm{MCRPC}$ patients with visceral disease progressing post docetaxel.

METHODS: In COU-AA-301, post-docetaxel mCRPC patients were randomized 2:1 to AA $1000 \mathrm{mg}(n=797)$ or placebo $(n=398)$ once daily, each with prednisone $5 \mathrm{mg}$ b.i.d. The primary end point was OS; secondary end points included radiographic progression-free survival (rPFS), PSA response rate and objective response rate (ORR). Treatment effects in visceral disease $(n=352)$ and non-visceral disease $(n=843)$ subsets were examined using final data (775 OS events).

RESULTS: AA plus prednisone produced similar absolute improvement in median OS in patients with (4.6 months) and without (4.8 months) visceral disease versus prednisone; hazard ratios (HRs) were 0.79 (95\% confidence interval $(\mathrm{Cl}): 0.60-1.05 ; P=0.102)$ and 0.69 (95\% Cl: $0.58-0.83 ; P<0.0001)$, respectively. Treatment with AA plus prednisone significantly and comparably improved secondary endpoint outcomes versus prednisone in both the subsets: the HRs for rPFS were $0.60(95 \% \mathrm{Cl}: 0.46-0.78 ; P=0.0002)$ and 0.68 (95\% Cl: $0.58-0.80 ; P<0.0001)$ in visceral and non-visceral disease subsets, respectively. PSA response rates were $28 \%$ versus $7 \%$ in the visceral disease subsets and $30 \%$ versus $5 \%$ in the non-visceral disease subsets (both $P<0.0001$ ), and ORRs were $11 \%$ versus $0 \%(P=0.0058)$ and $19 \%$ versus $5 \%(P=0.0010)$, respectively. The incidence of grade $3 / 4$ adverse events was similar between the subsets and between the treatment arms in each subset. Adverse events related to CYP17 blockade were increased in the $A A$ arms and were similar in patients with or without visceral disease.

CONCLUSIONS: AA plus prednisone provides significant clinical benefit, including improvements in OS and secondary end points, in post-docetaxel $\mathrm{mCRPC}$ patients with or without baseline visceral disease. The presence of visceral disease does not preclude clinical benefit from abiraterone.

Prostate Cancer and Prostatic Disease (2014) 17, 34-39; doi:10.1038/pcan.2013.41; published online 1 October 2013

Keywords: abiraterone acetate; liver metastases; metastatic prostate cancer; survival; visceral disease

\section{INTRODUCTION}

Visceral disease is a clinical manifestation of metastatic castrationresistant prostate cancer (MCRPC) with predominant lung and liver involvement. Subgroup analyses of recent clinical trials show that patients with visceral disease at baseline have particularly poor outcomes independent of the treatment assignment, with visceral disease identified as a negative prognostic factor. For example, in the TAX 327 study, which compared docetaxel plus prednisone versus mitoxantrone plus prednisone, median overall survival (OS) for all patients was 13.1 months for men with visceral disease compared with 18.9 months for those with only bone and/ or nodal involvement. ${ }^{1}$ In CALGB 90401, which evaluated the benefit of adding bevacizumab to docetaxel and prednisone, the median OS for all patients was 14.4 months in patients with baseline liver metastases compared with 22.6 months in those without such metastases. ${ }^{2}$ On the basis of comparable findings, visceral disease, or in some instances liver metastases, specifically, has been included in contemporary prognostic models. ${ }^{3-5}$ Prognostic modeling using TAX 327 data has shown visceral disease to be highly associated with decreased post-progression survival following first-line chemotherapy in men with $\mathrm{mCRPC}^{4}$ with liver metastases exhibiting more influence than overall visceral disease. ${ }^{3}$ However, visceral disease did not achieve multivariate significance because hepatic metastasis was underrepresented. ${ }^{3}$ Similarly, in their original report, Halabi et al. ${ }^{5}$ showed that visceral metastases were predictive of OS, based on univariate but not multivariate analysis. In a more recent analysis of the large ( $n=1901$ patients) denosumab versus zoledronic acid

${ }^{1}$ Department of Medical Oncology, Comprehensive Cancer Centers of Nevada, Las Vegas, NV, USA; ${ }^{2}$ University of Colorado Cancer Center, Aurora, CO, USA; ${ }^{3}$ Janssen Research \& Development, Los Angeles, CA, USA; ${ }^{4}$ Radboud University Medical Centre, Nijmegen, The Netherlands; ${ }^{5}$ Institut Gustave Roussy, University of Paris Sud, Villejuif, France; ${ }^{6}$ Urologikum Hamburg, Hamburg, Germany; ${ }^{7}$ Janssen Research \& Development, Raritan, NJ, USA; ${ }^{8}$ The Institute of Cancer Research and The Royal Marsden Hospital, Sutton, UK and ${ }^{9}$ Memorial Sloan-Kettering Cancer Center and Weill-Cornell Medical College, New York, NY, USA. Correspondence: Dr OB Goodman, Department of Medical Oncology, Comprehensive Cancer Centers of Nevada, 9280 W. Sunset Road, Ste \#100, Las Vegas, NV 89148, USA.

E-mail: Oscar.Goodman@USONCOLOGY.COM

This work was presented, in part, at the American Society of Clinical Oncology Genitourinary Cancers Symposium, 14-16 February 2013, Orlando, FL, USA, and at the European Association of Urology, 23rd Annual Congress, 15-19 March 2013, Milan, Italy

${ }^{10}$ These authors contributed equally to this work.

Received 9 July 2013; revised 26 July 2013; accepted 22 August 2013; published online 1 October 2013 
phase III study, ${ }^{6}$ however, visceral metastases were found to be an independent prognostic factor in men with bone metastases from CRPC. ${ }^{7}$ The Prostate Cancer Clinical Trials Working Group 2 (PCWG2) defines clinical subtypes based on patterns of disease spread, thus identifying patients with visceral disease with or without spread at other sites (subtype 5) as having the worst prognosis. $^{8}$

The prevalence of visceral disease in $\mathrm{MCRPC}$ is estimated at 5$24 \%$ based on study participants in first-line mCRPC studies performed prior to the approval of sipuleucel-T, ${ }^{9-11}$ and $8-15 \% \%^{8,12}$ based on post-chemotherapy trials. The relative importance of specific sites of visceral involvement is not clearly defined historically, but the most prevalent locations of visceral disease are the liver and lungs. In some instances, however, sites of metastatic disease are sometimes reported only for the liver, lungs and/or soft tissue (including nodal disease), and not specifically as visceral disease. ${ }^{8}$ According to the PCWG2 recommendations, the presence or absence of nodal disease and visceral disease at baseline as well as the post-treatment outcomes achieved in these subgroups should be reported separately. ${ }^{8}$ Notably, visceral disease is common in advanced prostate cancer, with one large autopsy series of 1589 prostate cancer patients reporting liver metastases in $25 \%$ and lung involvement in $46 \%$ of patients. ${ }^{13}$

Abiraterone acetate (AA) is a selective androgen biosynthesis inhibitor that blocks cytochrome P450 c17 (CYP17) to inhibit adrenal and intratumoral androgen synthesis. ${ }^{14,15}$ In the phase III COU-AA-301 trial, AA plus prednisone significantly improved OS in mCRPC patients previously treated with docetaxel, with an absolute median survival benefit of 4.6 months compared with prednisone alone (hazard ratio $(\mathrm{HR})=0.74 ; P<0.0001) .{ }^{16}$ These results led to the approval of AA plus prednisone for the treatment of $\mathrm{MCRPC}$ patients in more than 80 countries worldwide. The indication for $A A$ plus prednisone was recently expanded to include $\mathrm{MCRPC}$ patients who had not received prior chemotherapy based on the results of a subsequent phase III study (COU-AA-302). ${ }^{17}$

The objective of the present post hoc exploratory analysis of the COU-AA-301 trial was to determine whether the clinical benefits of AA plus prednisone on OS and other outcomes is maintained in post-docetaxel $\mathrm{mCRPC}$ patients with visceral disease compared with those patients with only bone and/or nodal involvement.

\section{MATERIALS AND METHODS}

\section{Study population}

Eligibility criteria for COU-AA-301 were described previously. ${ }^{16,18}$ Briefly, men with $\mathrm{MCRPC}$ were eligible if they had progressive disease following medical (luteinizing hormone-releasing analog therapy) or surgical castration and one or two regimens of prior cytotoxic chemotherapy, one of which included docetaxel. Eligibility required histological and cytological confirmation of adenocarcinoma of the prostate without neuroendocrine differentiation or small cell histology, and documented progression in PSA according to Prostate Cancer Working Group criteria, radiographic progression in bone or soft tissue according to the Response Evaluation Criteria in Solid Tumors (RECIST), or both PSA and radiographic progression. Metastatic disease was documented by bone scan, computed tomography or magnetic resonance imaging. Patients continued to receive ongoing androgen deprivation to maintain castrate serum testosterone levels $<50 \mathrm{ng} \mathrm{dl}^{-1}$, and had Eastern Cooperative Oncology Group (ECOG) performance status scores of $\leqslant 2$. All patients provided written informed consent prior to participating in the study.

\section{Study design and treatment}

COU-AA-301 was a phase III, multinational, randomized, double-blind placebo-controlled study comparing AA plus prednisone versus prednisone in men with $\mathrm{MCRPC}$ who had progressed post-docetaxel (Clinical Trials.gov identifier NCT00638690). ${ }^{16,18}$ Patients were enrolled from May 2008 through July 2009 at 147 sites in 13 countries, and randomly assigned in a 2:1 ratio to treatment with AA $1000 \mathrm{mg}$, taken once daily, plus prednisone or prednisone plus placebo. Patients in both groups received prednisone $5 \mathrm{mg}$ twice daily. The randomization was stratified by ECOG performance status ( $0-1$ versus 2 ), pain (present versus absent), number of prior chemotherapy regimens (one versus two) and type of progression (PSA only versus radiographic/PSA). The primary end point was OS, and prespecified secondary end points included radiographic progression-free survival (rPFS), PSA response rate, objective response rate (ORR) and time to PSA progression. The definition of each end point has been described previously. ${ }^{18}$ The study was approved by review boards at all participating institutions, and was conducted in accordance with the Declaration of Helsinki and the Good Clinical Practice Guideline of the International Conference on Harmonisation.

The current post hoc exploratory analysis was conducted in the subset with visceral disease, which included patients with liver, lungs or other soft tissue metastases at baseline, whether or not bone or nodal sites of disease were also present. Patients with both liver and lung metastases were included in the overall visceral disease population. The subset without visceral disease included patients with only bone and/or nodal sites of metastases. Visceral disease was defined according to the modified RECIST, with visceral lesions $\geqslant 1.0 \mathrm{~cm}$ in one dimension using spiral computed tomography considered target lesions. Outcome comparisons between these groups included OS and secondary end points.

\section{Statistical analysis}

The distributions of time-to-event variables were estimated using the Kaplan-Meier product limit method. The primary analysis for comparisons between treatments was conducted using the stratified log-rank test, with a Cox model used to obtain the HR and its associated 95\% confidence intervals $(\mathrm{Cls})$. The $\chi^{2}$ test was used in the treatment comparison of response rates.

\section{RESULTS}

\section{Patient characteristics}

In COU-AA-301, a total of 1195 patients were randomized to study treatment -797 to AA plus prednisone and 398 to prednisone. The visceral disease subset comprised 352 patients (29.5\% of the study cohort), 253 in the AA plus prednisone arm (31.7\%) and 99 in the prednisone arm (24.9\%) (Table 1). In the visceral disease subset $(n=352), 88(25 \%)$ had liver only metastases, $120(34 \%)$ had lung only metastases, 30 (9\%) had both liver and lung metastases and $114(32 \%)$ had visceral disease not involving the liver or lungs. Of these, 62 patients had visceral disease including prostate mass, 54 patients had visceral disease including other viscera that was widely dispersed at various sites throughout the body (bladder, $n=4$; adrenal gland, $n=2$; all other sites, $n=1$ ) and two patients had both prostate mass and other visceral involvement. To evaluate the specific impact of the site of disease, additional analysis was performed for the liver metastases and lung metastases groups. Patients with visceral disease, particularly those with liver metastases, had more clinically significant pain and higher baseline PSA, lactate dehydrogenase and ECOG performance status 2 compared with patients without visceral disease (Table 1).

The median duration of treatment with AA plus prednisone was 5.5 months (range: 0.2-24.1) compared with 3.1 months (range: 0.4-23.9) for prednisone in the visceral disease subset. The corresponding median durations of treatment in the subset without visceral disease were 8.2 months (range: $0.2-25.6$ ) and 3.7 months (range: $0.1-24.9$ ), respectively (data not shown).

\section{Outcomes}

Treatment with AA plus prednisone reduced the risk of death by $21 \%$ and $31 \%$ in patients with visceral disease or without visceral disease, respectively (Table 2 ). In the subset with visceral disease, median OS was 12.9 months with AA plus prednisone compared with 8.3 months with prednisone. Although there was a similar HR for superior survival with AA plus prednisone in the visceral disease group, this difference did not reach statistical significance 
Table 1. Baseline characteristics of the entire study cohort and the subsets with and without visceral disease

\begin{tabular}{|c|c|c|c|c|c|c|}
\hline \multirow[t]{2}{*}{ Baseline characteristics } & \multicolumn{2}{|c|}{ All patients } & \multicolumn{2}{|c|}{ Patients with visceral disease } & \multicolumn{2}{|c|}{ Patients without visceral disease } \\
\hline & $A A+P(\mathrm{n}=797)$ & $P(\mathrm{n}=398)$ & $A A+P(\mathrm{n}=253)$ & $P(\mathrm{n}=99)$ & $A A+P(\mathrm{n}=544)$ & $P(\mathrm{n}=299)$ \\
\hline Age (years): median (range) & $69(42-95)$ & $69(39-90)$ & $69(42-88)$ & $69(50-88)$ & $69.5(45-95)$ & $69(39-90)$ \\
\hline \multicolumn{7}{|l|}{ Extent of disease, $n$ (\%) } \\
\hline Bone & $710(89)$ & $358(90)$ & $218(86)$ & $87(88)$ & $492(91)$ & $271(92)$ \\
\hline Node & $361(45)$ & $164(41)$ & $124(49)$ & $44(44)$ & $237(44)$ & $120(41)$ \\
\hline Liver & $89(11)$ & $29(8)$ & $89(35)$ & $29(29)$ & 0 & 0 \\
\hline Lung & $105(13)$ & $45(11)$ & $105(42)$ & $45(46)$ & 0 & 0 \\
\hline Significant pain present, $n(\%)^{a, b}$ & $357(45)$ & $179(45)$ & $123(49)$ & $50(51)$ & $234(43)$ & $129(43)$ \\
\hline ECOG PS $2, n(\%)$ & $82(10)$ & $45(11)$ & $31(12)$ & $16(16)$ & $51(9)$ & $29(10)$ \\
\hline 2 prior chemotherapy regimens, $n(\%)^{\mathrm{a}}$ & $240(30)$ & $123(31)$ & $79(31)$ & $34(34)$ & $161(30)$ & $89(30)$ \\
\hline Radiographic progression, $n(\%)^{\mathrm{a}}$ & $559(70)$ & $273(69)$ & $196(78)$ & $68(69)$ & $363(67)$ & $205(69)$ \\
\hline Gleason score at initial diagnosis, $n(\%)$ & $(n=697)$ & $(n=350)$ & $(n=217)$ & $(n=86)$ & $(n=480)$ & $(n=264)$ \\
\hline$\leqslant 7$ & 341 (49) & $161(46)$ & $103(47)$ & $39(45)$ & $238(50)$ & $122(46)$ \\
\hline & $356(51)$ & $189(54)$ & $114(53)$ & $47(55)$ & $242(50)$ & $142(54)$ \\
\hline \multirow{3}{*}{ PSA (ng ml $\left.{ }^{-1}\right)$, median (range) } & $(n=788)$ & $(n=393)$ & $(n=248)$ & $(n=98)$ & $(n=540)$ & $(n=295)$ \\
\hline & 128.8 & 137.7 & 153.30 & 178.50 & 123.80 & 129.20 \\
\hline & $(0.4-9253)$ & $(0.6-10114)$ & $(0.7-9253)$ & $(0.6-5310)$ & $(0.4-5906)$ & $(3.2-100114)$ \\
\hline Median hemoglobin, $\mathrm{g} \mathrm{dl}^{-1}$ (range) & 11.8 & 11.8 & 11.5 & 11.5 & 11.9 & 11.9 \\
\hline & $(7.3-16.1)$ & $(7.2-16.5)$ & $(7.3-15.1)$ & $(7.2-16.4)$ & $(8.1-16.1)$ & $(8.1-16.5)$ \\
\hline Median LDH, IUI ${ }^{-1}$ (range) & 223 & 238 & 250 & 281 & 215 & 227 \\
\hline & (84-3373) & $(123-5125)$ & $(98-3373)$ & $(127-1400)$ & $(84-2145)$ & $(123-5125)$ \\
\hline Baseline CTC, median (range) & $5(0-2055)$ & $6(0-979)$ & $5(0-202)$ & $9(0-979)$ & $5(0-2055)$ & $6(0-253)$ \\
\hline
\end{tabular}

Table 2. Outcomes in patients with and without visceral disease at baseline

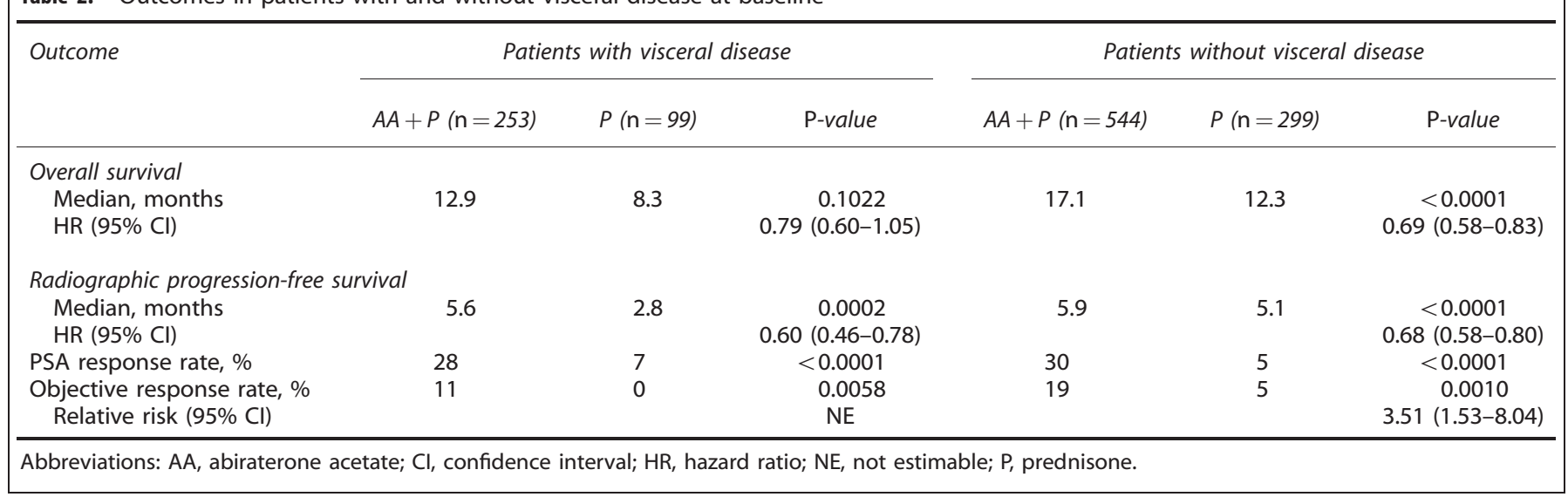

due to the much smaller sample size $(\mathrm{HR}=0.79 ; 95 \% \mathrm{Cl}: 0.60-1.05$; $P=0.102$ ) (Figure 1a). The corresponding median OS values in the subset without visceral disease were 17.1 months with AA plus prednisone and 12.3 months with prednisone $(\mathrm{HR}=0.69 ; 95 \% \mathrm{Cl}$ : $0.58-0.83 ; P<0.0001)$. The magnitude of the median survival benefit with AA plus prednisone compared with prednisone was similar in patients with visceral disease at baseline and those without visceral disease.

Treatment with AA plus prednisone significantly reduced the risk of radiographic progression or death by $40 \%$ and $32 \%$ in patients with visceral disease or without visceral disease, respectively (Table 2 ). Median rPFS was 5.6 months with AA plus prednisone compared with 2.8 months with prednisone in the visceral disease subset $(\mathrm{HR}=0.60 ; 95 \% \mathrm{Cl}: 0.46-0.78 ; P=0.0002)$, and 5.9 months and 5.1 months, respectively, in the subset without visceral disease $(\mathrm{HR}=0.68 ; 95 \% \mathrm{Cl}: 0.58-0.80 ; P<0.0001)$
(Figure $1 b)$. The HR in the subset with visceral disease $(0.60)$ was superior to that in the subset without visceral disease (0.68), which is likely a statistical artifact. Caution should be used in interpreting these results, as this was a secondary end point of the study and rPFS was not centrally reviewed. ORR and PSA response rates were also significantly higher with AA plus prednisone compared with prednisone in the visceral disease subset as well as in the subset without visceral disease (Table 2).

Next, we examined the prognostic and predictive impact of metastatic disease distribution. As described above, the visceral disease subset included 118 patients with liver metastases and 150 patients with lung metastases. Median OS was markedly shorter in the patients with liver metastases compared with lung metastases in the combined treatment groups (6.7 versus 12.0 months; HR (treatment effect: AA over prednisone) $=0.85 ; 95 \% \mathrm{Cl}$ : 0.60-1.22). However, median OS benefit was extended in both the 

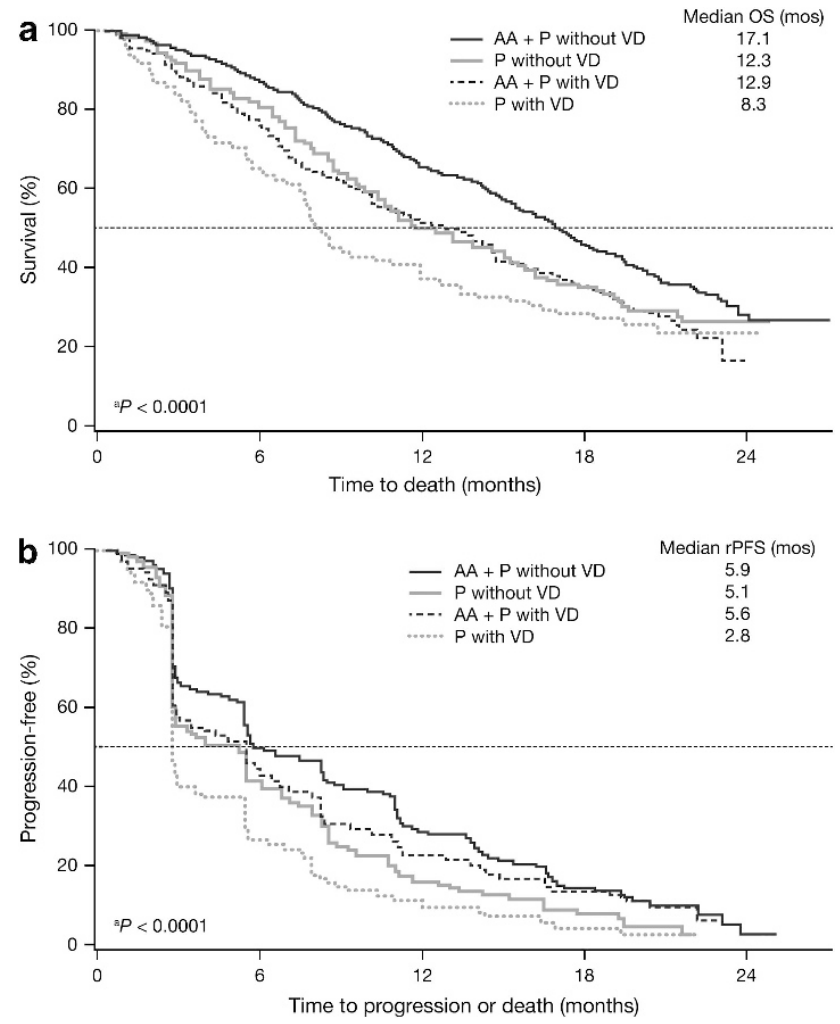

Figure 1. Kaplan-Meier estimates of overall survival (OS; a) and radiographic progression-free survival (rPFS; b) in the subsets with and without visceral disease at baseline. $A A$, abiraterone acetate; $P$, prednisone; VD, visceral disease; ${ }^{a}$ test of homogeneity of the 4 subgroups.

subsets by treatment with AA plus prednisone compared with prednisone: 7.3 versus 4.0 months in patients with liver metastases and 13.9 versus 7.9 months in patients with lung metastases (Table 3). AA plus prednisone produced objective responses in three patients $(4.1 \%)$ with liver metastases and nine patients $(12.2 \%)$ with lung metastases, including patients who had coexistent liver and lung disease, whereas none of the patients with liver or lung metastases responded to prednisone alone.

An assessment of the development of progressive visceral disease at the time of general progression showed that the most common location of new visceral disease in this setting was in the liver, followed by the lung. The proportion of those with progression of baseline visceral metastases versus new visceral involvement cannot be discerned from the available data. Any difference between the $A A$ plus prednisone group versus the prednisone group is difficult to interpret as the AA plus prednisone group had a higher percentage of patients with baseline visceral metastases and underwent a longer period of trial participation than the prednisone-treated patients.

\section{Safety and tolerability}

The incidence of grade 3/4 adverse events was similar among patients with or without visceral disease at baseline, and did not differ between treatment arms in either subset $(62 \%$ with AA plus prednisone and $65 \%$ with prednisone in the visceral disease subset, and $60 \%$ in each treatment arm in the subset without visceral disease). Adverse events of special interest observed more frequently in patients treated with AA plus prednisone (Table 4) were similar to those reported previously for the entire study cohort. ${ }^{16}$ The incidence of liver function test (LFT) abnormalities was higher in both treatment arms of patients with liver metastases compared with patients without liver metastases.
Table 3. Outcomes in patients with visceral disease by site

\begin{tabular}{lccc}
\hline Outcome & $A A+P$ & & $P$ \\
\hline $\begin{array}{c}\text { Lung metastases } \\
\text { Median OS, months }\end{array}$ & $(n=105)$ & & $(n=45)$ \\
Median rPFS, months & 13.9 & 12.0 & 7.9 \\
PSA response rate, \% & 5.6 & 3.8 & 2.8 \\
Liver metastases & 28.6 & & 6.7 \\
Median OS, months & $(n=89)$ & & $(n=29)$ \\
Median rPFS, months & 7.3 & 6.7 & 4.0 \\
PSA response rate, \% & 2.8 & 2.8 & 2.8 \\
\hline $\begin{array}{c}\text { Measurable disease } \\
\text { Lung metastases }\end{array}$ & 13.5 & & 3.5 \\
$\begin{array}{l}\text { ORR, \% } \\
\text { Liver metastases }\end{array} \quad(n=74)$ & & $(n=27)$ \\
ORR, \% & $(n=73)$ & & $(n=23)$ \\
& 4.1 & & 0
\end{tabular}

Abbreviations: AA, abiraterone acetate; ORR, objective response rate; OS, overall survival; $\mathrm{P}$, prednisone; rPFS, radiographic progression-free survival. ${ }^{a}$ At baseline.

\begin{tabular}{|lccccc|}
\hline Table 4. Incidence (any grade) of adverse events of special interest \\
\hline Incidence, \% & $\begin{array}{c}\text { Patients with liver } \\
\text { metastases }\end{array}$ & & $\begin{array}{c}\text { Patients without liver } \\
\text { metastases }\end{array}$ \\
\cline { 2 - 3 } \cline { 5 - 5 } & $\begin{array}{c}A A+P \\
(\mathrm{n}=88)\end{array}$ & $\begin{array}{c}P \\
(\mathrm{n}=28)\end{array}$ & $\begin{array}{c}A A+P \\
(\mathrm{n}=703)\end{array}$ & $\begin{array}{c}P \\
(\mathrm{n}=366)\end{array}$ \\
\hline $\begin{array}{l}\text { Fluid retention/ } \\
\text { edema }\end{array}$ & 36.4 & 28.6 & 32.6 & 23.5 \\
$\begin{array}{l}\text { LFT } \\
\text { abnormalities }\end{array}$ & 19.3 & 14.3 & 10.2 & 8.5 \\
$\begin{array}{l}\text { Cardiac } \\
\text { disorders }\end{array}$ & 15.9 & 7.1 & 15.9 & 12.0 \\
$\begin{array}{l}\text { Hypokalemia } \\
\text { Hypertension }\end{array}$ & 15.9 & 7.1 & 18.3 & 9.3 \\
\hline $\begin{array}{l}\text { Abbreviations: AA, } \\
\text { prednisone. } \\
\text { aHigher incidence of LFT abnormalities is to be expected in patients with } \\
\text { liver involvement. }\end{array}$ & 3.4 & 0 & 12.1 & 8.7 \\
\hline
\end{tabular}

\section{DISCUSSION}

Visceral disease has long been considered a negative prognostic factor in mCRPC. However, in older studies of the disease, visceral disease was not defined, nor was the impact of specific sites of involvement clearly delineated. Despite this, a working understanding of visceral disease in prostate cancer as non-nodal, soft tissue disease has emerged. With the cohort described here, which includes a substantial number of patients with as well as without visceral disease, we have an opportunity to gain additional insight into the natural history of visceral disease in MCRPC.

The findings of this study confirm the prognostic importance of visceral disease in MCRPC. With the additional evaluation of the impact of the site of visceral involvement, liver metastases are shown to have a greater negative prognostic effect than lung disease. This finding is consistent with those of contemporary clinical trials, such as CALGB 90401 and TAX 327, which showed that visceral disease, particularly liver metastases, is an adverse prognostic factor in mCRPC patients regardless of treatment. ${ }^{1,2}$ This is also consistent with other urologic tumors such as testis cancer, with its well-defined prognostic scale emphasizing 
nonpulmonary visceral metastases as an independent and potent driver of poor prognosis. ${ }^{19}$

Although visceral disease has a negative prognostic effect, it is not predictive of the response to $A A$ or of resistance to $A A$, even in patients with advanced disease who fit the definition of CRPC. Median OS was extended by 4.6 months in the visceral disease subset and by 4.8 months in the subset without visceral disease. Assessing by site of involvement, benefit of AA was observed in patients with either lung or liver metastases as shown by improvement in OS from 7.9 to 13.9 months and from 4.0 to 7.3 months, respectively. Likewise, the ORR was significantly higher in the patients treated with $A A$ in both the group with lung metastases and the group with liver metastases. In addition, in a recently reported study of the androgen receptor signaling inhibitor enzalutamide in a study population similar to that of COU-AA-301, the use of enzalutamide was associated with a higher PSA response rate and improved rPFS and OS in patients with or without visceral (liver and lung) involvement. ${ }^{20}$ These findings support the recognition of the prognostic importance of visceral disease (especially liver involvement) in the design of future $\mathrm{MCRPC}$ trials as a stratification factor, but not an exclusion criterion, to ensure proportional representation during randomization of subjects. It should be noted that in patients without prior chemotherapy, in Study COU-AA-302, ${ }^{17}$ patients with visceral disease were excluded, whereas in the PREVAIL study of enzalutamide these patients were included. ${ }^{21}$ Besides these insights into the natural history of visceral disease in $\mathrm{mCRPC}$, specific findings pertinent to the use of $A A$ are also recognized. The present analysis shows that $A A$ plus prednisone has meaningful efficacy and provides comparable clinical benefit in $\mathrm{MCRPC}$ patients with visceral disease at baseline and in those without visceral disease, as evidenced by improvements in ORR, PSA response rate and rPFS.

The safety and tolerability of AA in MCRPC patients with visceral disease were similar to those reported previously for the entire study cohort. Adverse events were predominantly grade 1 or 2 , and no differences in the incidence of grade 3/4 adverse events were observed between the subsets with or without visceral disease, or between treatment arms within these subsets. Moreover, adverse events that were mechanism based and secondary to mineralocorticoid excess resulting from CYP17 blockade, including fluid retention, hypokalemia and hypertension-although more common with AA plus prednisone than with prednisone-occurred at similar rates in patients with or without visceral disease. The incidence of LFT abnormalities was higher in both treatment arms of patients with liver metastases versus those without liver metastases, thereby suggesting a direct influence of metastatic disease to the liver on the LFT abnormalities in some of these patients $(18.1 \%$ versus $9.6 \%$, respectively). AA has been associated with the development of LFT abnormalities, and a higher incidence of LFT abnormalities would be anticipated in patients with visceral disease who received AA. Overall, the presence of visceral disease at baseline does not negatively impact the safety and tolerability profile of AA. As in the entire study cohort, adverse events were easily managed and reversible in the subset with visceral disease.

It should be noted that patients with neuroendocrine differentiation were explicitly excluded from this study, so we were not able to assess the visceral disease progression in patients with a distinct anaplastic phenotype. Further studies in the $\mathrm{MCRPC}$ population would be of interest to determine the response to AA and any relation to PSA levels. In addition, this was a post hoc analysis with reduced number of patients for the visceral disease subsets that did not allow for valid determination of statistical differences in response based on PSA levels.

In summary, these data indicate that AA plus prednisone is an active therapeutic option for MCRPC patients, including those with more advanced disease associated with the presence of liver and/or lung metastases. Nevertheless, additional treatments are needed to improve the poor prognosis of mCRPC patients with liver metastases.

\section{CONFLICT OF INTEREST}

Oscar B Goodman, Jr. has served as a consultant and received payment for lectures from Veridex LLC, a division of Johnson \& Johnson. Thomas W Flaig has received grants from Cougar, Veridex, Medivation, Amgen, Sanofi-Aventis and BNIT Therapeutics; travel support from Cougar; honoraria from Amgen; and has served as a consultant to Sanofi-Aventis and GTX. Arturo Molina is an employee of Janssen Research \& Development and owns stock in Johnson \& Johnson. Peter FA Mulders has nothing to disclose. Karim Fizazi has served in a consultant/advisory role for and received honoraria from Janssen Research \& Development. Henrik Suttmann has received a grant, honorarium and travel support from Janssen-Cilag; has served as a board member for Ferring, Janssen-Cilag and Astellas, and as a consultant for Ferring, Janssen-Cilag, Ipsen, Astellas, medac and Sanofi-Aventis; has received a grant from Astellas; honoraria from Ipsen, medac, Janssen-Cilag, Ferring and SanofiAventis; and travel support from Bayer, Pfizer and Takeda. Jinhui Li is an employee of Janssen Research \& Development and owns stock in Johnson \& Johnson. Thian Kheoh is an employee of Janssen Research \& Development and owns stock in Johnson \& Johnson. Johann $S$ de Bono has received honoraria from Astellas, AstraZeneca and Johnson \& Johnson, and is an employee of The Institute of Cancer Research, which has a commercial and patent interest in abiraterone. Howard I Scher has received research funding from the Prostate Cancer Foundation as well as from Aragon, Bristol-Myers Squibb, Exelixis, Janssen Research \& Development, Janssen Global Services and Medivation; has acted as a compensated consultant/advisor to Dendreon, Endo/Orion Pharmaceuticals, Genentech, Novartis, Ortho Biotech Oncology Research \& Development (now Janssen Research \& Development; proceeds donated); and has acted as an uncompensated consultant/advisor to Aragon, Celgene, Exelixis, Foundation Medicine, Janssen, Johnson \& Johnson Pharmaceutical Research \& Development, Medivation, Millennium Pharmaceuticals and Takeda. His institution, Memorial Sloan-Kettering Cancer Center, has received research funding from the Prostate Cancer Foundation.

\section{ACKNOWLEDGEMENTS}

This work was supported by funding from Janssen Research \& Developmen (formerly Ortho Biotech Oncology Research \& Development, unit of Cougar Biotechnology). Ira Mills, PhD, of PAREXEL provided writing assistance, which was funded by Janssen Global Services, LLC.

\section{REFERENCES}

1 Berthold DR, Pond GR, Soban F, de WR, Eisenberger M, Tannock IF. Docetaxel plus prednisone or mitoxantrone plus prednisone for advanced prostate cancer updated survival in the TAX 327 study. J Clin Oncol 2008; 26: 242-245.

2 Kelly WK, Halabi S, Carducci MA, George DJ, Mahoney JF, Stadler WM et al. Liver metastases (LM) to predict for short overall survival (OS) in metastatic castration-resistant prostate cancer (mCRPC) patients (pts). J Clin Oncol 2012; 30 (Suppl 15) (abstract 4655).

3 Armstrong AJ, Garrett-Mayer ES, Yang YC, de WR, Tannock IF, Eisenberger M. A contemporary prognostic nomogram for men with hormone-refractory metastatic prostate cancer: a TAX327 study analysis. Clin Cancer Res 2007; 13 6396-6403.

4 Armstrong AJ, Garrett-Mayer E, de WR, Tannock I, Eisenberger M. Prediction of survival following first-line chemotherapy in men with castration-resistant metastatic prostate cancer. Clin Cancer Res 2010; 16: 203-211.

5 Halabi S, Small EJ, Kantoff PW, Kattan MW, Kaplan EB, Dawson NA et al. Prognostic model for predicting survival in men with hormone-refractory metastatic prostate cancer. J Clin Oncol 2003; 21: 1232-1237.

6 Fizazi K, Carducci M, Smith M, Damião R, Brown J, Karsh L et al. Denosumab versus zoledronic acid for treatment of bone metastases in men with castration-resistant prostate cancer: a randomised, double-blind study. Lancet 2011; 377: 813-822.

7 Fizazi K, Massard C, Smith M, Rader EM, Brown JE, P Milecki et al. Baseline covariates impacting overall survival (OS) in a phase 3 study of men with bone metastases from castration-resistant prostate cancer. J Clin Oncol 2012; 30 (Suppl 15) (abstract 4642)

8 Scher HI, Halabi S, Tannock I, Morris M, Sternberg CN, Carducci MA et al. Design and end points of clinical trials for patients with progressive prostate cancer and castrate levels of testosterone: recommendations of the Prostate Cancer Clinical Trials Working Group. J Clin Oncol 2008; 26: 1148-1159. 
9 Petrylak DP, Tangen CM, Hussain MH, Lara Jr PN, Jones JA, Taplin ME et al. Docetaxel and estramustine compared with mitoxantrone and prednisone for advanced refractory prostate cancer. N Engl J Med 2004; 351: 1513-1520.

10 Small EJ, Halabi S, Dawson NA, Stadler WM, Rini Bl, Picus J et al. Antiandrogen withdrawal alone or in combination with ketoconazole in androgen-independent prostate cancer patients: a phase III trial (CALGB 9583). J Clin Oncol 2004; 22: 1025-1033.

11 Tannock IF, de WR, Berry WR, Horti J, Pluzanska A, Chi KN et al. Docetaxel plus prednisone or mitoxantrone plus prednisone for advanced prostate cancer. $N$ Engl J Med 2004; 351: 1502-1512.

12 Fizazi KS, Higano CS, Nelson JB, Gleave M, Miller K, Morris T et al. Phase III, randomized, placebo-controlled study of docetaxel in combination with zibotentan in patients with metastatic castration-resistant prostate cancer. J Clin Oncol 2013; 31: 1740-1747.

13 Bubendorf L, Schopfer A, Wagner U, Sauter G, Moch H, Willi N et al. Metastatic patterns of prostate cancer: an autopsy study of 1,589 patients. Hum Pathol 2000; 31: $578-583$.

14 Attard G, Reid AH, Yap TA, Raynaud F, Dowsett M, Settatree S et al. Phase I clinical trial of a selective inhibitor of CYP17, abiraterone acetate, confirms that castration-resistant prostate cancer commonly remains hormone driven. J Clin Oncol 2008; 26: 4563-4571.

15 O'Donnell A, Judson I, Dowsett M, Raynaud F, Dearnaley D, Mason M et al. Hormonal impact of the 17alpha-hydroxylase/C $(17,20)$-lyase inhibitor abiraterone acetate (CB7630) in patients with prostate cancer. Br J Cancer 2004; 90: 2317-2325.
16 Fizazi K, Scher HI, Molina A, Logothetis CJ, Chi KN, Jones RJ et al. Abiraterone acetate for treatment of metastatic castration-resistant prostate cancer: final overall survival analysis of the COU-AA-301 randomised, double-blind, placebocontrolled phase 3 study. Lancet Oncol 2012; 13: 983-992.

17 Ryan CJ, Smith MR, de Bono JS, Molina A, Logothetis CJ, de Souza P et al. Abiraterone in metastatic prostate cancer without previous chemotherapy. $N$ Engl J Med 2013; 368: 138-148.

18 de Bono JS, Logothetis CJ, Molina A, Fizazi K, North S, Chu L et al. Abiraterone and increased survival in metastatic prostate cancer. N Engl J Med 2011; 364: 1995-2005.

19 Leman ES, Gonzalgo ML. Prognostic features and markers for testicular cancer management. Indian J Urol 2010; 26: 76-81.

20 Loriot Y, Fizazi K, de Bono JS, Forer D, Hirmand M, Scher HI. Outcomes in patients with liver or lung metastatic castration-resistant prostate cancer (mCRPC) treated with the androgen receptor inhibitor enzalutamide: results from the phase III AFFIRM trial. J Clin Oncol 2013; 31 (Suppl 15) (abstract 5065).

21 A safety and efficacy study of oral MDV3100 in chemotherapy-naive patients with progressive metastatic prostate cancer (PREVAIL). ClinicalTrials.gov. http:// clinicaltrials.gov/show/NCT01212991. Accessed 18 June 2013.

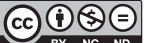

This work is licensed under a Creative Commons AttributionNonCommercial-NoDerivs 3.0 Unported License. To view a copy of this license, visit http://creativecommons.org/licenses/by-nc-nd/3.0/ 